\title{
La estrategia de Arabia Saudí en el Consejo de Cooperación del Golfo. Espacios de cooperación y conflicto
}

\section{Saudi Arabia's Strategy in the Gulf Cooperation Council: Spaces for Cooperation and Conflict}

\author{
PALOMA GONZÁLEZ DEL MIÑO \\ Universidad Complutense de Madrid, España \\ DAVID HERNÁNDEZ MARTÍNEZ \\ Universidad Autónoma de Madrid, España
}

Resumen: El Consejo de Cooperación para los Estados Árabes del Golfo es la organización regional más importante de Oriente Medio. Desde la década de 1980, ha servido para impulsar la integración económica y política de las seis monarquías que lo constituyen. Tras la Primavera Árabe de 2011, la tensión entre los miembros ha crecido debido a los diferentes intereses manifestados ante las crisis locales. En el Consejo predomina la influencia de Arabia Saudí. El rey Salmán y el príncipe Mohammed bin Salmán intentan reforzar el liderazgo saudí sobre el resto de los socios con el propósito de construir una

Recepción: 2 de agosto de 2019. / Aceptación: 23 de abril de 2020. 
política exterior común dirigida desde Riad. Sin embargo, los otros países del Consejo, especialmente Catar, no comparten plenamente sus objetivos, por lo que se ha abierto un periodo de enorme confrontación interna que desestabiliza por completo la zona y pone en riesgo la perdurabilidad de la organización y los mecanismos de integración. El artículo analiza el papel de la organización en las estrategias de seguridad y cooperación regional y presta atención al papel desempeñado por Arabia Saudí y a las tensiones surgidas entre los socios.

Palabras clave: Arabia Saudí; Consejo de Cooperación del Golfo; hegemonía; política exterior; estrategia regional.

Abstract: The Cooperation Council for the Arab States of the Gulf is the most important regional organization in the Middle East. Since the 1980s, it has boosted the economic and political integration of its six member states, all of which are monarchies. After the Arab Spring of 2011, local crises triggered increasing tensions among its members due to their conflicting interests. The Council is the Saudi Arabia's primary area of influence. King Salman and Prince-Crown Mohammed bin Salman intend to reinforce the Saudi leadership over the rest of the partners to build a Riyadh-led common foreign policy. However, their goals are not fully shared by other Council countries, especially by Qatar, starting a period of severe internal rifts. This is completely destabilizing the local area and jeopardizing the organization's sustainability and integration mechanism. This paper analyzes the organization's role in regional cooperation and security strategies, focusing on Saudi Arabia's role and the emerging tensions between the partners.

Key words: Saudi Arabia; Gulf Cooperation Council; hegemony; foreign policy; regional strategy.

\section{Introducción}

El Consejo de Cooperación para los Estados Árabes del Golfo, creado en 1981 por Arabia Saudí, Omán, Emiratos Árabes Unidos, Catar, Bahréin y Kuwait, es la organización regional más 
relevante en Oriente Medio. Durante más de treinta años ha sido un enclave de integración funcional que sirve de punto de encuentro de estos regímenes para abordar desafíos y amenazas regionales. Sin embargo, ya no goza de unanimidad debido a que las prioridades de cada Estado han variado en aspectos fundamentales, como la seguridad o las relaciones con terceros países. Estas circunstancias impiden una mayor cooperación entre los gobiernos y quiebran la aparente unidad que los ha caracterizado durante décadas.

Arabia Saudí ocupa un espacio destacado en la organización y siempre ha pretendido convertirla en una herramienta más de su política exterior para establecer su zona de influencia natural y frenar a su vez injerencias de otras potencias. Las intenciones saudíes enfrentan la desconfianza de sus homólogos. Los otros cinco socios muestran actitudes distintas ante el papel preponderante saudí dentro de la organización. Bahréin o Emiratos Árabes Unidos están en gran sintonía con los postulados de la casa Saud y han implementado una política exterior muy vinculada a las premisas de Riad. El emirato de Kuwait y el sultanato de Omán intentan alcanzar mayores cotas de autonomía en sus relaciones internacionales, por lo que evitan caer en una total discrepancia con el líder regional. Catar es el único país que manifiesta una tensión creciente con los saudíes debido a que ejerce una política exterior activa en el contexto regional, tiene un hábil manejo comunicacional de la cadena Al Jazeera y busca un espacio propio y destacado en el entorno.

La respuesta del Consejo ante los acontecimientos ocurridos desde 2011 remarca dos cuestiones centrales: primera, algunos miembros están abandonando su tradicional papel secundario y han favorecido una política exterior más robusta y proactiva; segunda, la organización todavía no presenta un marco operativo consolidado para actuar como una institución política y económica cohesionada. La crisis diplomática con Catar a partir de 2017 supone un serio obstáculo para fortalecer las interdependencias entre estos países y pone en duda la propia viabilidad de la organización regional. 
El artículo analiza la evolución del Consejo desde la década de 1980 hasta la actualidad, y examina con detenimiento la estrategia de Arabia Saudí. El trabajo parte de tres supuestos: i) la Primavera Árabe provocó profundas transformaciones en el statu quo de Oriente Medio y ha obligado a los gobiernos a redefinir sus prioridades; ii) no existe una respuesta conjunta de las seis monarquías a las crisis locales coetáneas, lo que ha originado numerosas tensiones entre estos países, y iii) el rey Salmán y el príncipe Mohammed bin Salmán han introducido importantes cambios en la política exterior del reino, que han tenido consecuencias directas en el funcionamiento del Consejo.

La investigación se asienta en la siguiente premisa: pese a las convergencias identitarias y los intereses comunes en el plano internacional, entre algunos miembros se verifican reticencias respecto al papel hegemónico de Arabia Saudí, así como resistencias a formular una política exterior y de seguridad común que implique la limitación de cotas de soberanía en ámbitos concretos. Estas circunstancias lastran la capacidad de actuación conjunta y congruente de la organización ante las crisis locales actuales, debido a la ausencia de planteamientos estratégicos y consensuados entre sus miembros, lo que deriva en un funcionamiento cada vez más deficitario y errático.

El objeto de estudio es la estrategia regional de Arabia Saudí para el Consejo en el contexto posterior a la Primavera Árabe, especialmente a partir de 2015, con las medidas tomadas por el rey Salmán y su heredero al trono, el príncipe Mohammed bin Salmán. El análisis se centra en evaluar la relación entre el Estado saudí y cada una de las cinco monarquías del Consejo; asimismo, se explican los puntos de concordancia en sus agendas regionales y los temas de mayor divergencia y tensión. En las conclusiones se discuten los logros más reseñables y los principales fracasos de la integración, así como los posibles escenarios políticos tras las recientes diferencias surgidas entre los socios. 


\section{El proceso de integración del Consejo de Cooperación del Golfo}

El Consejo (25 de mayo de 1981) se constituyó en un contexto internacional y regional complejo y convulso. La guerra Irán-Iraq, iniciada en 1980 entre la recién instaurada república islámica de los ayatolas y el régimen baazista de Sadam Hussein, suponía una seria amenaza para la seguridad y la integridad de las monarquías árabes de la zona (Fabani 2009). La Guerra Fría se encontraba en uno de los periodos de mayor hostilidad entre la Unión Soviética y Estados Unidos, y la rivalidad entre ambas potencias se trasladó a distintos escenarios del mundo y afectó directamente las dinámicas locales de Oriente Medio.

A principios de la década de 1970 se produjo el final del Protectorado británico en gran parte del Golfo, con el consiguiente repliegue de los intereses europeos en la zona. Sin embargo, los emiratos recién independizados, como Kuwait, Bahréin, Catar, Emiratos Árabes Unidos, más Omán y el reino de Arabia Saudí, quedaron en la práctica bajo la protección de Estados Unidos (Mainuddin 2016, 165-166). La potencia estadounidense promovió la colaboración entre estos seis Estados con la intención de constituir un bloque que sirviera de contención de los regímenes iraní e iraquí, contrarios a la fuerte presencia estadounidense. Además, los modelos políticos de Irán e Iraq y sus aspiraciones regionales suponían para las dinastías árabes una seria alternativa a sus gobiernos.

Desde 1981 hasta 2019, en la evolución del Consejo se aprecian diversas fases condicionadas, en parte, por los grandes acontecimientos que tuvieron lugar en Oriente Medio y en el resto de la sociedad internacional. En la primera fase, 1981-1991, se consolidó la organización; en la segunda, 1991-2001, se profundizó la integración; en la tercera, 2001-2011, hubo una expansión política y económica, y, por último, de 2011 a 2019 ocurrieron la crisis y la confrontación interna.

La década de 1980 fue el periodo de afianzamiento de la organización, mientras que los otros dos Estados vecinos, Iraq 
e Irán, se debilitaron mutuamente en un conflicto de 10 años. Los primeros esfuerzos del Consejo se focalizaron en crear canales de cooperación en seguridad y defensa y dieron lugar, en 1985, a la Fuerza del Escudo de la Península (Nadal 2016). Este aparato militar está compuesto por casi 10000 efectivos de los seis países miembros y surgió ante el temor de una posible invasión de iraníes o iraquíes. Su función principal era actuar como elemento disuasorio y de defensa común ante las agresiones militares que sufriera algún país de la organización.

La década de 1990 comenzó con un hecho traumático para las monarquías del Golfo: la invasión de Kuwait. La rápida derrota del régimen kuwaití y la anexión al Estado iraquí confirmaron los grandes temores del resto de las monarquías. La intervención internacional liderada por Estados Unidos permitió aislar al régimen de Sadam Hussein y reducir la inestabilidad local. Las dinastías fueron partidarias de mejorar sus sistemas de defensa con grandes inversiones públicas, mientras reforzaban individualmente las alianzas militares con la potencia estadounidense. El Consejo adquirió un cariz distinto al promover mecanismos de cooperación económica y política, en tanto el asunto de la seguridad quedó relegado a un tema interno.

El primer decenio del siglo XXI vino marcado por dos acontecimientos rupturistas del statu quo en la región: por un lado, el 11-S y el auge del terrorismo yihadista a escala internacional, en que algunos países, como Arabia Saudí y Catar, fueron señalados por sus confusos vínculos con determinadas organizaciones; y, por otro, la guerra de Iraq en 2003, que supuso una nueva brecha en la compleja relación con la administración estadounidense (Lacey 2009, 295-302). Washington llevó a cabo una acción a gran escala en Iraq sin contar con el consenso y el respaldo claros de la mayoría de las monarquías árabes, que lo consideraron desde entonces como un factor desestabilizador.

Estos excepcionales episodios coincidieron con una época de crecimiento económico y estabilidad interna. Los seis miembros del Consejo poseen $40 \%$ de las reservas comprobadas de 
petróleo del mundo y $20 \%$ de las de gas natural (Bouoiyour y Selmi 2019). Los réditos de la explotación de estas reservas sirven a los gobiernos para tres fines: i) reforzar su autoridad entre la población al mejorar los resortes estatales de represión; ii) promover la modernización y el desarrollo de los países bajo el axioma de un modelo rentista y clientelar (Saldaña 2011), y iii) afianzar la política exterior mediante la ampliación de sus intereses a escala regional e internacional. Es una fase de amplios consensos en el Consejo, que conformó la Unión Aduanera en 2003 y el Mercado Común en 2008.

El periodo de 2011 a 2019 representó una fase trascendental para el devenir político de Oriente Medio y el Golfo. Las revueltas árabes marcaron una brecha en las relaciones regionales que afectó el funcionamiento del Consejo. Las diversas crisis evidenciaron la disparidad de intereses entre los miembros, especialmente entre Catar y Arabia Saudí (Haykel 2013). Estas desavenencias han provocado que los seis miembros no sean capaces de dar una respuesta conjunta a los diferentes problemas. A esta coyuntura se le suma un ciclo de bajos precios de los hidrocarburos que mina los recursos y las capacidades de las petromonarquías para mantener políticas expansionistas en materia internacional.

\section{Distintas estrategias de seguridad y defensa}

Los acontecimientos sucedidos tras la Primavera Árabe representan un importante impedimento para mejorar la colaboración entre los Estados miembros, ya que las percepciones sobre el grado de amenaza y peligro difieren ostensiblemente en cada régimen. Las monarquías siguen defendiendo su autonomía en temas centrales de seguridad para la propia perdurabilidad de sus dinastías. El interés de Riad por constituir una organización unida choca con las apreciaciones a este respecto de los demás socios, que no quieren sustituir el amparo estadounidense por la delimitante tutela de los Saud. 
Las estrategias de seguridad y defensa de cada régimen fueron muy semejantes hasta el nuevo siglo. Desde la Segunda Guerra Mundial, Estados Unidos fue ganando peso en la zona, inicialmente al consolidar sus relaciones con la extinta monarquía persa y el reino de Arabia Saudí. Ambos países actuaban como contrapesos ante los movimientos nacionalistas y panarabistas que emergieron en todo Oriente Medio y el Magreb (Ulrichsen 2011, 82-83). La alianza de estos dos países con la potencia occidental determinaría sus estrategias de seguridad y defensa hasta el estallido de la Revolución iraní en 1979, que supuso una ruptura en la correlación de fuerzas en la región.

El Golfo se convirtió en una prioridad para la política exterior de Estados Unidos, que consideró esencial tener una posición dominante en ese enclave para controlar toda la franja árabe y el cinturón musulmán (Khalifé 2017, 145-146). La alianza con la casa Saud y el sha de Irán estuvo cimentada en tres esferas: defensa, petróleo y reconocimiento. Las distintas administraciones estadounidenses se comprometieron a garantizar la defensa de los regímenes y a ser sus principales valedores internacionales; a cambio, estos países se convertirían en suministradores de petróleo y gas para las economías occidentales, mientras la seguridad quedaba como asunto interno.

A finales de la década de 1960 y principios de la de 1970, cuando Kuwait, Catar, Bahréin, Emiratos Árabes Unidos y Omán alcanzaron su independencia del Reino Unido, rápidamente pasaron a quedar bajo el amparo de la Casa Blanca (Pollack 2002, 78-79). Tomaron el ejemplo de la estrategia seguida por Arabia Saudí e Irán, confiando su defensa a las fuerzas estadounidenses, estrechando lazos comerciales con las potencias occidentales y vertebrando sus propios sistemas nacionales de seguridad. La amenaza real de una agresión externa quedó reducida en aquel entonces. Las máximas preocupaciones se concentraban en evitar corrientes revolucionarias en sus territorios. 
Entre la guerra del Golfo de 1991 y el 11-S hubo un periodo de transición en las diferentes políticas nacionales. La invasión de Sadam Hussein a Kuwait evidenció la fragilidad de la mayoría de las monarquías, que sin la atención de Estados Unidos eran incapaces de repeler a terceros Estados. La victoria de la coalición internacional sirvió para ampliar la presencia militar estadounidense y mejorar la cooperación con el conjunto del Consejo (Commins 2012, 250-252). Había un consenso generalizado de que tanto el sistema iraquí como la República Islámica de Irán representaban serias amenazas para las dinastías cercanas, aunque la conformidad de enemigos compartidos no llegó a traducirse en el amparo y la potenciación de nuevos espacios de defensa común.

El auge yihadista añadió una nueva amenaza para los dirigentes árabes. La seguridad se había centrado hasta entonces en reprimir cualquier tipo de movimientos opositores en el orden interno, pero algunas corrientes se radicalizaron ante la permisividad de las autoridades nacionales. Las células terroristas implicaban una crítica frontal y violenta contra el statu quo. Algunos gobiernos, como el saudí, quedaron señalados por sus presuntos vínculos con organizaciones extremistas, lo que derivó en una fractura respecto a la confianza en la administración Bush. La rápida expansión de este fenómeno obligó a adaptar las actuaciones de los servicios de inteligencia para frenar su alcance.

Hasta 2003, las estrategias de seguridad y defensa fueron muy homogéneas entre los seis miembros del Consejo, centradas en la asistencia y la colaboración con terceras potencias internacionales, aunque hubo ciertas peculiaridades en relación con los saudíes. La presencia militar de Estados Unidos en el reino fue siempre negada por los Saud (Pollack 2003, 8-9), ya que los sectores más conservadores del wahabismo criticaron la posibilidad del establecimiento de tropas extranjeras en el país. Sin embargo, el resto de las monarquías permitió las bases militares y el paso de unidades occidentales.

El derrocamiento de Saddam Hussein y el vacío de poder en Iraq motivaron que los gobiernos de la zona reformularan 
sus programas de seguridad y comenzaran a manifestarse ciertas divergencias en los objetivos de cada uno de los países y en la relación con su aliado estadounidense. Para Catar, Omán y Bahréin, la defensa fue en este periodo una cuestión secundaria, y confiaban todavía en el amparo de potencias extranjeras. Los saudíes lideraron un cambio de posición y prestaron una considerable atención a las inversiones en el sector militar (Wezeman 2018). La inestabilidad generada en Iraq y las ambiciones nucleares de Irán fueron motivos suficientes para que la corona saudí planteara la necesidad de militarizar sus objetivos regionales.

El gasto militar en la zona ha crecido notablemente; se trata de una de las áreas del mundo donde mayores inversiones se hacen en estos sectores debido, en parte, al cuantioso gasto de Arabia Saudí y otros de sus socios del Consejo. El gobierno saudí dedicó cerca de 13\% de su PIB a gasto militar; Omán, 14\%; Emiratos Árabes Unidos, 8\%; mientras que Bahréin, Kuwait y Catar destinaron a ese rubro entre 3 y 4\% del PIB para 2015-2017 (Cordesman y Harrington 2018). El Golfo se convirtió, en estas circunstancias, en un enclave sumamente militarizado, a lo que se añade la presencia de tropas estadounidenses, francesas, británicas y, más recientemente, turcas, tras la crisis catarí.

Las diferencias con Catar derivaron, en 2017, en un bloqueo económico y político por parte de Arabia Saudí, Emiratos Árabes Unidos, Bahréin y Egipto. La situación abrió, entre los socios del Consejo (Negri 2018, 244-246), una nueva brecha que determinaría la paralización casi completa de la organización en los siguientes años. Se produjo una variación significativa en los márgenes de seguridad en el Golfo, ya que para los cataríes la amenaza real de un ataque no provenía de potencias extranjeras, sino que podía propiciarse por la ofensiva de uno de sus socios. Esta circunstancia rompió las posibilidades de llegar a un entendimiento y generó un clima de absoluta tensión. 


\section{Arabia Saudí en el Consejo de Cooperación del Golfo: primus inter pares}

La importancia que el Consejo tiene para Arabia Saudí se aprecia con claridad en función del análisis de los principios de su política exterior. La monarquía saudí considera que debe ocupar un papel central en Oriente Medio y en el ámbito musulmán por una conjunción de factores religiosos y políticos (Ottaway 2011). En el país se encuentran La Meca y Medina, que conceden al territorio nacional un estatus especial en la idiosincrasia del islam. Además, la corriente predominante en el reino es el wahabismo, que se erige a sí mismo como la única interpretación correcta de la palabra del Profeta.

El discurso wahabita está en total consonancia con el poder de la dinastía Saud, que ha sido su principal valedor durante siglos. El wahabismo es el elemento legitimador más importante para la monarquía de Arabia Saudí: ayuda a los príncipes a presentarse ante sus conciudadanos y el resto de la comunidad musulmana como los baluartes de la auténtica fe (Valentine 2015, 19-26). De esta forma, el gobierno saudí cuenta con una vasta argumentación religiosa que justifica sus aspiraciones de ocupar una posición hegemónica dentro de Oriente Medio y la esfera musulmana.

El Estado se vale de la narrativa religiosa y de sus alianzas con terceros países para consagrarse como un estandarte de estabilidad, así como un frente de contención ante las sucesivas corrientes de cambio. Su histórica alianza con Estados Unidos lo presenta como un socio fiable para Occidente. Además, Arabia Saudí ocupa una posición estratégica de suma importancia para el equilibrio regional e internacional al estar situada en el centro de la península arábiga, entre el mar Rojo y el Golfo. Cuenta con las segundas mayores reservas probadas de petróleo del mundo, lo que ha contribuido a que emprenda una ambiciosa política de modernización y ampliación de sus capacidades militares (Saab 2014). Todos estos elementos geopolíticos, económicos y religiosos convierten al país en una potencia en Oriente Medio. 
La política exterior de Arabia Saudí se proyecta en función de esferas de interés para la monarquía (Hernández 2019, 215 217). El primer nivel se circunscribe al Golfo e incluye a los miembros del Consejo, Irán, Iraq y Yemen por su situación fronteriza, y a Estados Unidos debido a su notable presencia en la zona. El segundo nivel se centra en los países árabes de Oriente Medio e Israel. En penúltimo lugar, la esfera islámica incluye todas aquellas naciones del mundo donde el islam tiene una fuerte presencia institucional y social. Finalmente, el cuarto nivel o escala internacional concentra distintos países o regiones del mundo consideradas no tan importantes.

Arabia Saudí es vista como el líder natural de la región, especialmente en su área de máxima prioridad: el Golfo. Desde la constitución del Consejo, los saudíes han tenido una extrema preocupación por hacer prevalecer sus intereses en el seno de la organización y evitar las interferencias del poder iraní en el área. Es también una cuestión de seguridad para la propia monarquía de los Saud (Nonneman 2005, 331-332), ya que hay una fuerte correlación entre lo que pueda ocurrir en el entorno y la estabilidad del reino.

La estrategia de Arabia Saudí en el Consejo y en Oriente Medio no ha sido otra que la de reforzar su liderazgo, por lo que se presentan ante el resto de los países bajo el principio de primus inter pares (Ehteshami 2012, 264-265). Este hecho, junto con los recelos del resto de las dinastías por ceder cotas de soberanía en terrenos como la defensa o la política exterior, incide en la frágil integración de los seis países. Las pretensiones saudíes no son compartidas, en mayor o menor medida, por el resto de los miembros, que se encuentran ante un serio dilema. Kuwait, Emiratos Árabes Unidos, Bahréin, Omán y Catar no quieren quedar subyugados por la hegemonía saudí, pero tampoco pueden romper la relación con el país árabe, que es un referente en Oriente Medio y en el ámbito musulmán. 


\section{La estrategia saudí ante los cambios regionales}

La incidencia de la Primavera Árabe fue reducida entre las monarquías del Golfo; solamente en el emirato bahreiní se vivió una situación límite entre los meses de febrero y marzo de 2011. La inestabilidad interna fue sofocada por la intervención directa de dispositivos de la Fuerza del Escudo de la Península (Espinosa 2011), conformada principalmente por militares saudíes y policías de Emiratos Árabes Unidos. Fue la primera vez que esta fuerza se desplegó en el territorio de un Estado miembro no por una agresión externa, sino para ayudar al gobierno a contener las protestas ciudadanas.

Arabia Saudí puso especial énfasis en la intervención militar de Bahréin por varias razones: i) evitar que una monarquía aliada pudiera caer y que el vacío fuera ocupado por otro actor político menos afín; ii) frenar las revueltas en el archipiélago bahreiní para contener un posible efecto contagio en su propio territorio (Mabon 2012); iii) lanzar un mensaje de firmeza al exterior con la ratificación de la autoridad de los Saud en el Golfo sobre las pretensiones iraníes, y iv) utilizar la operación para reforzar la imagen interna de la corona y del wahabismo ante el creciente malestar de algunos sectores de la sociedad.

La acción sobre Bahréin abrió una fisura en el seno de la organización; en primer lugar, porque no todos los miembros apreciaron la gran amenaza de las revueltas, y, en segundo, porque algunos gobiernos estimaron como un peligroso precedente utilizar la Fuerza del Escudo de la Península no con propósitos defensivos sino para cuestiones de seguridad interna. Los acontecimientos posteriores sólo sirvieron para confirmar que las prioridades cataríes estaban alejadas de los objetivos saudíes (Priego 2015). Para la dinastía Al Thani, los cambios en Oriente Medio supusieron una oportunidad para ampliar la autonomía exterior del emirato construyendo su propia imagen en la zona. Para la familia Saud, todas estas transformaciones supusieron un serio peligro para su estatus de líder. 
Las recientes tensiones entre ambos países exhiben la vulnerabilidad del liderazgo de Riad en su esfera natural de influencia. El emirato con enormes reservas de gas ha ido implementando una política exterior activa y demostrando a los otros que el tamaño, en cuanto a extensión y número de habitantes - menos de medio millón de nativos-, no es un factor decisivo. La conjunción de una mayor autonomía en política exterior a través de vínculos con Israel, los movimientos islamistas como Hamás y Hezbolá, las relaciones tibias con Irán, el apoyo diplomático y logístico a los levantamientos en Libia, Siria y Yemen, la influencia de Al Jazeera, o la activa diplomacia cultural, contrasta con el deseo de cierto control que quisiera ejercer Arabia Saudí y que escapa a su influencia sobre el pequeño país insular.

En el periodo 2013-2014, Arabia Saudí presionó diplomáticamente a Catar para que recondujera sus operaciones en Oriente Medio. Se unieron a ese plan otros Estados, como Egipto, Emiratos Árabes Unidos y Bahréin, que retiraron a sus embajadores del país catarí. En una segunda fase, desde 2017, los saudíes lideraron un bloqueo económico y político (Sarto 2018), bajo la amenaza de emprender acciones más fuertes. La política saudí fue secundada de nuevo por egipcios, emiratíes y bahreiníes, pero no consiguió arrastrar a otros países y la situación quedó enquistada sin que ninguna de las partes mostrara signos de querer conciliar posturas.

La crisis con Catar produjo un panorama regional muy incierto y confuso. Por un lado, Arabia Saudí ha fracasado en su intención de imponer su postura al resto de los miembros del Consejo y de utilizar el tema catarí como otra muestra de su poder. De hecho, el gobierno catarí ha encontrado aliados inesperados en Turquía e Irán (Barnes-Dacey, Geranmayeh y Lovatt 2018). Por otro lado, la tensión entre cataríes, saudíes, emiratíes y bahreiníes ha fomentado una crispación política y social sin precedentes entre estas monarquías y que dificulta el acercamiento de posturas y la posibilidad de un nuevo consenso general. El Consejo queda muy debilitado tras esta profunda división interna. 
Yemen no es miembro del Consejo, pero es uno de los actores más importantes en la agenda regional de Arabia Saudí, que siempre lo ha considerado un espacio natural de su poder. Para la monarquía árabe, tiene una calidad semejante a la de los miembros del Consejo (Lynch 2016, 236-237). Los saudíes han intentado incluir al país yemení dentro de la organización del Golfo; sin embargo, se han encontrado con las reticencias de los demás socios. La inestabilidad y la inseguridad internas se alegan como los principales motivos para frenar la incorporación yemení. El conflicto civil posterior a la Primavera Árabe puso de relieve la relevancia de este Estado para el liderazgo de los Saud.

Las revueltas en los primeros meses de 2011 se entremezclaron rápidamente con tensiones territoriales. Yemen logró la reunificación en 1991, pero no solventó las divisiones tribales. El presidente Saleh consiguió mantenerse en el poder, en un difícil equilibrio de intereses, durante más de tres décadas. A comienzos del siglo XxI, Arabia Saudí estrechó relaciones con el gobierno central de Saná y lo incorporó a su círculo de influencia (Hernández 2020). La posibilidad de una guerra en la frontera sur suponía un notable riesgo para la seguridad nacional saudí. Por ello, los Saud, a través del Consejo, intentaron canalizar una salida pacífica a la violencia creciente en el país.

Arabia Saudí tenía claro cuáles eran sus prioridades en Yemen: primero, asegurar que las diversas rivalidades no desembocaran en un conflicto bélico, y, en segundo término, lograr que el poder siguiera estando en manos de algún actor de confianza. El Consejo actuó como mediador hasta 2015 y consiguió que Saleh renunciara a su cargo y se estableciera un espacio de diálogo nacional (Blecua 2015). El proceso de paz cayó en 2014, cuando los hutíes del norte lograron hacerse con el control de gran parte del país. En marzo de 2015, el régimen decidió variar su estrategia y emprender una operación militar que coincidió con la llegada de un nuevo monarca al trono de Riad.

La intervención saudí en territorio yemení se explica por dos razones: por un lado, porque para los intereses de la casa 
Saud suponía un peligro que el grupo de los hutíes pudiera tomar el control; por otro, porque el príncipe Mohammed bin Salmán podía utilizar el conflicto como ejercicio de fuerza para anunciar que la monarquía retomaba una política regional más ofensiva. Arabia Saudí consiguió el apoyo del Consejo y otros aliados, pero la violencia continuó en Yemen y se ha tornado en uno de los focos de Oriente Medio más desestructurados en las esferas política, económica y social, con una de las mayores crisis humanitarias acontecidas desde la Segunda Guerra Mundial.

Irán representa la principal amenaza a la hegemonía saudí en Oriente Medio, especialmente en el Golfo. Las crisis regionales posteriores a la Primavera Árabe han servido al poder iraní para fortalecer su posición en el mapa local. El régimen de los ayatolas aspira a consolidar un eje de alianzas transversales a lo largo de varios puntos (Sadeghi-Boroujerdi 2017, 162-165), como Siria, Iraq, Líbano, Gaza o Yemen. El objetivo es alcanzar un papel preponderante a través del reforzamiento de su poder y su influencia regionales. Estos intereses chocan radicalmente con las intenciones de Arabia Saudí y sus aliados.

La estrategia del reino saudí respecto al problema iraní ha ido variando según las circunstancias, aunque persigue los mismos propósitos desde el principio: reducir y debilitar el auge de Irán en la región, y fortalecer la presencia de Arabia Saudí frente a la iraní en aquellos frentes primordiales para sus intereses nacionales. La incompatibilidad de la política regional iraní y de la estrategia saudí radica en que ambos Estados aspiran a ocupar la misma posición de liderazgo en Oriente Medio.

Irán da todo su apoyo económico y militar al régimen de Bashar al-Assad en Siria y sustenta a grupos religiosos y políticos en Iraq, Líbano y Palestina, mientras aprovecha la guerra en Yemen para aproximarse a los hutíes y estrechar vínculos con Catar en plena crisis diplomática con Arabia Saudí (Rodríguez 2018). Por su parte, el rey Salmán se ha alineado con la administración de Donald Trump y el ejecutivo israelí de Netan- 
yahu, lo que ha dado lugar a un acercamiento sin precedentes entre el Estado de Israel y el reino saudí. Estas circunstancias han motivado que los dirigentes saudíes releguen la cuestión palestina y se posicionen cada vez más cerca de las autoridades israelíes.

Bahréin y Emiratos Árabes Unidos suscriben las directrices de Arabia Saudí, contrarios a favorecer que Irán consiga mayor protagonismo en la escena regional. Sin embargo, Kuwait y Omán desarrollan una actitud comedida, conscientes de la importancia de preservar buenas relaciones tanto con los Saud como con los iraníes. Debido al bloqueo económico, Catar es la monarquía que más se acerca al poder de los ayatolas (Vatanka 2012), donde ha encontrado un aliado frente a la presión saudí. En esta situación, desde Riad se empiezan a tejer otras coaliciones con países de Oriente Medio y el Magreb que dejan de lado al Consejo.

Las transformaciones en la política exterior inducidas por el rey Salmán y el príncipe Mohammed bin Salmán desde 2015 forman parte de un conjunto de grandes cambios en el ámbito interno y externo. La reactivación de la estrategia regional y el plan Saudi Vision 2030 son las dos grandes iniciativas planteadas por el gobierno saudí. El programa económico de reformas pretende mejorar la competitividad de Arabia Saudí, reducir su dependencia del petróleo, diversificar su estructura productiva y ampliar los ingresos estatales (Nurunnabi 2017, 356-358). Con todo ello, la corona de los Saud pretende conservar el reino como una potencia política, religiosa y económica.

\section{Las monarquías árabes del Consejo de Cooperación del Golfo y Arabia Saudí}

La unidad del Consejo pasa por una fase de enorme fragilidad y deterioro. La reciente crisis con Catar, prolongada desde 2017 hasta la actualidad, en la que Arabia Saudí lidera un bloqueo económico y comercial secundada, entre otros, por Emiratos 
Árabes Unidos y Bahréin (Alarcón 2018), conduce a la mayor división en la historia de la organización. El emirato catarí no está dispuesto a renunciar a algunos de sus principios en materia de política exterior. Este persistente problema y las posturas desiguales de los miembros del Consejo subrayan que: i) no existe un mínimo acuerdo para construir una estrategia regional conjunta; ii) el reino saudí no consigue hacer prevalelecer sus intereses por encima de las prioridades de los demás, y iii) estas circunstancias están dando lugar a relaciones desiguales entre las monarquías árabes, basadas en variados grados de confianza.

Arabia Saudí, Bahréin y Emiratos Árabes Unidos componen un bloque propio dentro del Consejo. La política regional de estos tres países es muy homogénea. La respuesta a las crisis locales se da de forma muy coordinada, siempre con los saudíes en un papel referencial. A esta triple alianza se incorporó el gobierno egipcio del general Al Sisi desde 2013 (Katz 2014, 79-80). El inicio de esta coalición ocurrió tras las revueltas en territorio bahreiní en 2011, cuando tanto saudíes como emiratíes eran los primeros en asistir a la familia Al Jalifa. Desde entonces, los tres países desarrollan conjuntamente diferentes acciones diplomáticas y de carácter militar.

Los pilares sobre los que se asienta la coordinación entre este particular triunvirato, y en último lugar Egipto, son fundamentalmente tres: $i$ ) defensa del statu quo interno de cada país y protección mutua de los regímenes; ii) freno a cualquier tipo de injerencia de terceros actores, y iii) actuación conjunta para recuperar márgenes de seguridad y estabilidad en la región. Con estos principios, los tres socios del Consejo, junto con los egipcios, han consolidado una postura común en temas como Yemen, Siria, Catar y el ascenso iraní.

Las movilizaciones en Bahréin hicieron que Arabia Saudí y Emiratos Árabes Unidos asumieran que los miembros del Consejo no estaban exentos de un contagio revolucionario. La situación bahreiní presentaba dos agravantes: la posibilidad de que cayera la familia real y que ello sirviera de ejemplo para más 
revueltas en la zona, y la inquietud de que el vacío de poder fuera ocupado por un actor político no cercano a sus intereses. Los bahreiníes y los emiratíes tienen pendientes disputas territoriales con Irán (Al-Mazrouei 2015) que los llevan a sumarse a la animadversión que la corona saudí tiene contra el régimen de los ayatolas. El eje chiita es uno de los principales factores que puede desestabilizar uno de los tres países.

En las regiones costeras del golfo de Arabia Saudí, donde se localizan los principales yacimientos de petróleo y gas, hay una considerable población chiita (Soage 2017). La monarquía árabe teme que estos sectores sean alentados por Irán para favorecer la desestabilización del reino. La misma intranquilidad es compartida por Emiratos Árabes Unidos y Bahréin, donde existen núcleos de población chiita, y a esto se suman los problemas territoriales con el país iraní. Los tres gobiernos intentan empujar al Consejo a tomar una posición más beligerante contra Teherán, pero Catar, Omán y Kuwait no los secundan.

Bajo el supuesto de frenar cualquier cambio en el statu quo local, Arabia Saudí, Emiratos Árabes Unidos y Bahréin siempre se mostraron contrarios al gobierno de los Hermanos Musulmanes en Egipto, pues representaba la contraposición a su modelo político (González del Miño 2017, 136-137). Además, el presidente Morsi comenzó a tejer una relación estrecha con el ejecutivo de Irán. Por estas razones, creció el malestar de los saudíes ante el apoyo decidido de los cataríes al nuevo ejecutivo en El Cairo. Ésta fue una de las principales causas que darían lugar a la primera crisis entre ambos países en 2014.

Arabia Saudí se mostró, ante el resto de los gobiernos vecinos, como el respaldo inquebrantable y consiguió atraer a su círculo de influencia a Bahréin y a Al Sisi de Egipto, a quienes también les facilitó ayuda financiera para sus economías (Nordland 2013). La relación entre bahreiníes y saudíes es claramente desigual, ya que la dependencia política y económica de Manamá respecto a Riad ha crecido desde 2011. Los Saud son el principal soporte de su aliado bahreiní y el gobierno de 
los Al Jalifa no tiene otra opción que la de alinearse con la política regional del rey Salmán.

El caso de Emiratos Árabes Unidos es muy distinto al de Bahréin, pues la federación de emiratos no tiene una relación de dependencia, ya que cuenta con recursos económicos y capacidades militares considerables (Davidson 2011, 24-25) que le permiten ampliar sus márgenes de influencia regional. El estrecho vínculo con Arabia Saudí se produjo por la congruencia de intereses. Los responsables en Abu Dhabi comparten el objetivo de reducir el alcance del poder iraní en el Golfo y de restablecer cierto orden en las dinámicas locales. Además, consideran inapropiadas las políticas emprendidas por Qatar en el entorno, sobre todo las asociaciones tan estrechas con actores como los Hermanos Musulmanes, el ejecutivo de Erdogan o el régimen de Teherán, que son considerados una amenaza real para los dirigentes emiratíes.

Un posicionamiento intermedio es el representado por Omán y Kuwait, que optan por preservar una conducta de bajo perfil y calculada imagen mediadora hacia el exterior, y evitan inmiscuirse de manera activa en los principales puntos conflictivos de la región. Las razones de esta estrategia son dos: aislar sus territorios de los incidentes de alrededor y no formar parte de ninguno de los bloques que se constituyen en la región, para no levantar malestar entre las potencias vecinas.

Kuwait tiene una delicada posición. Una parte de su población es chiita, colinda con Irán y los vínculos económicos entre ambos son importantes. Estos hechos justifican que no mantenga un punto de vista muy crítico hacia el poder iraní, pero tampoco quiere contravenir a Arabia Saudí, ya que los saudíes son un socio cercano. En el caso de Omán, el sultán Al Said lleva más de treinta años en el poder (Manea 2005, 94-95) conservando los difíciles equilibrios tribales. Estas circunstancias lo han llevado a ejercer una política exterior poco llamativa que rehúye la intervención en disputas regionales. No obstante, son los kuwaitíes y los omaníes quienes han desempeñado un papel de mediadores en el conflicto entre Catar y el resto de las 
monarquías árabes con el doble propósito de impedir una escalada de la tensión y mantener operativa la organización.

\section{La crisis con Catar y la unidad del Consejo de Cooperación del Golfo}

La crisis diplomática con el emirato catarí en 2014, junto con el bloqueo económico de 2017, supusieron en el seno del Consejo una profunda brecha que frenó por completo las posibilidades de mayor integración. La razón última de esta fricción se debe a la complicada relación entre la casa Saud y la dinastía Al Thani. Arabia Saudí defiende un tipo de coalición en la que aspiran a ser el primus inter pares, en tanto que los cataríes buscan espacios de cooperación poco vinculantes, que no limiten sus intereses. La política exterior de Catar ha pasado por diferentes etapas en las últimas dos décadas (Roberts 2016): desde ser un actor regional poco relevante, a ocupar una posición de mediador $\mathrm{y}$, finalmente, a convertirse en parte activa del mapa político tras 2011.

Mientras los postulados de Catar no colisionaron con las estrategias de Arabia Saudí, no hubo problemas entre ambos. Para la monarquía saudí no fue inconveniente que el pequeño emirato catarí decidiera jugar un papel mediador en asuntos como el conflicto en Sudán, las divisiones internas en Líbano o las rivalidades en Yemen antes de la Primavera Árabe (Barakat 2014, 15-19). El Estado saudí era el líder incuestionable de Oriente Medio, pero entonces los Al Thani entendieron que tenían la suficiente capacidad para construir una política exterior más ambiciosa, que les permitiera proteger sus intereses sin depender de potencias externas.

Catar es uno de los principales exportadores de gas y posee las segundas reservas del mundo después de Rusia. La explotación de estos recursos representa la mitad del PIB nacional y $70 \%$ de los ingresos estatales (Cochrane 2017). Con tal respaldo económico, el gobierno decidió asumir un nuevo papel en el 
escenario internacional y regional tras las revueltas árabes. Su presencia es destacada en distintos puntos de Oriente Medio y el Magreb, como Libia, Egipto o Siria (Ulrichsen 2014, 8-15). Estas acciones unilaterales y el apoyo a diferentes facciones sobre el terreno contradicen la posición de Riad. Los Al Thani ven una oportunidad en las revueltas y los conflictos para consagrarse como actores clave de la zona sin la necesidad del amparo saudí.

El malestar de Arabia Saudí por la estrategia catarí tras la Primavera Árabe se debió a dos causas: sus acciones en Libia, Egipto o Siria no fueron consensuadas con el resto de los miembros, y los apoyos de Catar a algunos grupos rebeldes libios y sirios, pero, sobre todo, su respaldo decidido a los Hermanos Musulmanes en la rebelión egipcia (Khatib 2014, 4-7), contravenían los intereses de los saudíes y del resto de las monarquías. Se rompió la confianza entre los dos gobiernos y ello se tradujo en una tensión creciente que estallaría en el bloqueo económico de 2017.

El gobierno de los Saud y sus más estrechos aliados intentaron presionar a Catar para revertir algunas de sus estrategias. En 2014, cuando saudíes, bahreiníes y emiratíes retiraron a sus embajadores de Doha (Hassan 2015), buscaron debilitar la imagen exterior de los Al Thani. A partir de 2017, con el bloqueo económico intentaron directamente aislarlo. No obstante, Arabia Saudí no ha conseguido los apoyos esperados en cuanto a la presión sobre el emirato catarí, y se mantiene al margen de la disputa entre Kuwait y Omán y la potencia estadounidense. Además, el acercamiento entre cataríes, turcos e iraníes ha dificultado la solución de las diferencias dentro del Consejo.

\section{Conclusiones}

Las relaciones entre Arabia Saudí y el resto de las monarquías árabes del Consejo de Cooperación para los Estados Árabes del 
Golfo han variado en las últimas décadas; de un clima de cordialidad y cooperación se ha pasado a una fase de profunda división. Los cambios acontecidos tras la Primavera Árabe propiciaron una crisis de confianza sin precedentes dentro de la organización. Los saudíes no sólo son incapaces de encabezar respuestas conjuntas, sino que también aparecen como un elemento disruptivo debido a la pretensión de preservar sus intereses en el nuevo statu quo local, al intentar plasmar un multilateralismo cimentado en su posición preponderante. Este tipo de planteamiento motiva una polarización creciente de las dinámicas regionales, limita los posibles espacios de entendimiento y aumenta los niveles de tensión.

El Consejo es la organización política regional más importante. Durante casi cuatro décadas ha habido avances significativos en la integración de los seis países. La seguridad y la defensa fueron los temas que promovieron el encuentro de saudíes, cataríes, kuwaitíes, bahreiníes, emiratíes y omaníes, pero poco a poco la economía fue dominando la agenda común. El principal obstáculo para un grado mayor de vinculación e integración está en el aspecto netamente político. Las prioridades de cada gobierno llegan a ser difícilmente compatibles en asuntos tan determinantes. Los regímenes autoritarios rechazan perder competencias en ámbitos tan sensibles como la defensa o la política exterior, sobre todo en un periodo clave para la región.

Mientras el entorno local fue propicio para los intereses de cada una de las monarquías, las tensiones entre los gobiernos fueron escasas y el diálogo y el entendimiento prevalecieron. Las crisis regionales surgidas tras las revueltas de 2011 exhibieron las debilidades del Consejo, que nunca lograron resolverse. Arabia Saudí, Bahréin y Emiratos Árabes Unidos percibieron las transformaciones en Oriente Medio como una auténtica amenaza para sus intereses y buscaron que los otros socios respondieran en la misma línea. Sin embargo, Catar entendió las nuevas coyunturas como una oportunidad idónea para mejorar su estatus internacional. Asimismo, Kuwait y Omán 
apostaron por una actitud cautelosa que los distanció de las posteriores controversias acaecidas en el Golfo.

Arabia Saudí considera las vicisitudes actuales en el orden regional como un serio contratiempo para su liderazgo y, por esta razón, aboga por una acción colectiva del Consejo, siempre bajo la autoridad y las premisas de la casa Saud. Estas premisas son parcialmente compartidas por el gobierno de Bahréin, que ha tenido varios episodios de revueltas a lo largo de estos años, y por el ejecutivo de Emiratos Árabes Unidos, sobre todo por el temor creciente a un mayor protagonismo iraní en el Golfo. Además, los príncipes saudíes trabajan por incorporar a su marco de influencia a otros países árabes, como Egipto. No obstante, Catar, Omán y Kuwait no secundan la estrategia saudí porque no quieren quedar bajo su dominio en un periodo transcendental para la estabilidad en la región.

La incapacidad para construir vínculos políticos más fuertes resurge ahora con fuerza y se manifiesta como debilidad de la organización. Los temas de seguridad y política exterior son los dos vectores que destacan la heterogeneidad de las preferencias, puesto que Catar, Kuwait y Omán no están dispuestos a renunciar a cotas de autonomía a cambio de fortalecer una integración dirigida únicamente por Arabia Saudí. El resultado de este problemático contexto es una organización regional casi paralizada, en la que predominan la desconfianza y la creciente rivalidad entre algunos de sus socios.

Los cambios en la política exterior de Arabia Saudí introducidos por el rey Salmán y el príncipe Mohammed bin Salmán luego de las profundas transformaciones en el statu quo de Oriente Medio tienen consecuencias directas sobre el Consejo y la relación entre las monarquías árabes. Las disparidades de amenazas en el entorno y el liderazgo polarizado saudí tienen como consecuencia que no se lleguen a vertebrar mecanismos integradores en seguridad y acción exterior. La mayor parte de los socios prefiere implementar sus propios planes, porque la perciben como la estrategia más segura ante la inestabilidad 
regional, y también como el medio para reducir las injerencias de los saudíes en sus regímenes.

Arabia Saudí aún persiste en presionar a Catar para que vuelva a su círculo de influencia, al tiempo que intenta reforzar alianzas con países como Egipto, Jordania o Marruecos para ampliar un eje netamente saudí. La crisis catarí y la ampliación de la esfera de los Saud con otros Estados de Oriente Medio, el Magreb y África subsahariana sólo favorecen el paulatino deterioro del Consejo. La organización deja de ser un punto de integración regional para erigirse en un espacio de encuentro endeble entre monarquías que no logran superar sus diferencias y alcanzar un mínimo consenso. El Consejo sufre una de las mayores crisis de su historia debido no tanto a su praxis y su operatividad, sino a la ausencia de un interés compartido por parte de sus miembros.

\section{Referencias}

Alarcón, Jorge, 2018. "La crisis de Catar y sus repercusiones en el Golfo Arábigo”. Diálogo Político, 22 de mayo de 2018.

Al-Mazrouei, Noura. S. 2015. Disputed Islands between UAE and Iran: Abu Musa, Greater Tunb, and Lesser Tunb in the Strait of Hormuz (GRM Papers). Cambridge: Gulf Research Centre Cambridge. https://www.files.ethz.ch/isn/194095/GRM_Noura_ paper_30-09-15_new_7634.pdf

BaraKat, Sultan. 2014. Qatari Mediation: Between Ambition and Achievement (Brookings Doha Center Analysis Paper 12). Washington: Brookings Institution. https://www.brookings. $\mathrm{edu} / \mathrm{research} /$ qatari-mediation-between-ambition-and-achievement/

Barnes-Dacey, Julien, Ellie Geranmayeh y Hugh Lovatt. 2018. The Middle East's New Battle Lines (ECFR Policy Brief 259). Londres: European Council on Foreign Relations. https://www.ecfr.eu/ page/-/The_Middle_Easts_New_Battle_Lines.pdf

BLECUA, Ramón. 2015. "Üna revolución en la revolución: los houthi y las nuevas relaciones de poder en Yemen”. ARI 21/2015. Real 
Instituto Elcano, 13 de abril. http://www.realinstitutoelcano. org/wps/portal/rielcano_es/contenido?WCM_GLOBAL_ CONTEXT =/elcano/elcano_es/zonas_es/mediterraneo $+y+$ mundo + arabe/ari21-2015-blecua-revolucion-en-revolucionhouthi-y-nuevas-relaciones-de-poder-en-yemen

Bouoryour, Jamal y Refk Selmi. 2019. “The Qatar-Gulf Crisis and Risk Management in Oil and Gas Markets". Preprint, enviado el 17 de abril. https://hal.archives-ouvertes.fr/hal02101633

Cochrane, Paul. 2017. "Gas and the Gulf Crisis: How Qatar could Gain the Upper Hand”. Middle East Eye, 27 de junio de 2017.

Commins, David. 2012. The Gulf States. A Modern History. Londres:

I. B. Tauris. https://doi.org/10.5040/9780755608805

CoRdesman, Antony H. y Nicholas Harrington. 2018. The Arab Gulf States and Iran: Military Spending, Modernization and the Shifting Military Balance [Second Working Draft]. Washington: Center for Strategic and International Studies. https://www.csis.org/analysis/arab-gulf-states-and-iran-military-spending-modernizationand-shifting-military-balance

Davidson, Christopher M., ed. 2011. Power and Politics in the Persian Gulf Monarchies. Londres: Hurst.

Ehteshami, Anoushiravan. 2012. "Security and Strategic Trends in the Middle East". En The Transformation of the Gulf. Politics, Economics and the Global Order, editado por David Held y Kristian Ulrichsen, 261-277. Nueva York: Routledge.

EspinOSA, Ángeles. 2011. “Arabia Saudí envía tropas a Bahréin”. El País, 15 de marzo de 2011.

FABANI, Ornela. 2009. "Orígenes y evolución del Consejo de Cooperación de Estados Árabes del Golfo”. Ponencia presentada en el XIX Simposio Electrónico Internacional Medio Oriente y Norte de África, Centro de Estudios Internacionales para el Desarrollo, 28 de septiembre al 22 de octubre de 2009. http://www.ceid.edu. ar/biblioteca/2009/ornela_fabani_origenes_y_evolucion_ del_consejo_de_cooperacion_de_estados_arabes_del_golfo. $\mathrm{pdf}$

GonZÁleZ DEL MiÑo, Paloma. 2017. Egipto. 2011-2017: alteraciones en las redes de poder. Madrid: Los Libros de la Catarata.

Hassan, Islam Khalid. 2015. GCC's 2014 Crisis: Causes, Issues and Solutions (Dossier). Doha: Al Jazeera Centre for Studies. http:// 
studies.aljazeera.net/en/dossiers/2015/03/201533172623652531. html

Haykel, Bernard. 2013. Saudi Arabia and Qatar in a Time of Revolution (Gulf Analysis Paper). Washington: Center for Strategic \& International Studies Middle East Program. https://www. csis.org/analysis/gulf-analysis-paper-saudi-arabia-and-qatar-timerevolution

HernándeZ, David. 2019. "La política exterior de Arabia Saudí en Oriente Medio tras la primavera árabe. Objetivos y estrategias regionales (2011-2016)". Tesis doctoral. Universidad Complutense de Madrid. https://eprints.ucm.es/51661/

Hernández, David. 2020. El reino de Arabia Saudí y la hegemonía de Oriente Medio. Madrid: Catarata.

KATZ, Mark N. 2014. "The International Relations of the Arab Spring”. Middle East Policy 21, núm. 2 (verano): 76-84. https:// doi.org/10.1111/mepo.12072

Khalifé, Nabil. 2017. The Attempt to Uproot Sunni-Arab Influence. A Geo-Strategic Analysis of the Western, Israeli and Iranian Quest for Domination. Traducido por Joseph A. Kéchichian. Brighton: Sussex Academic Press.

Kнатів, Lina. 2014. Qatar and the Recalibration of Power in the Gulf. Washington: Carnegie Endowment for International Peace. https://carnegieendowment.org/files/qatar_recalibration. pdf

LACEY, Robert. 2009. Inside the Kingdom. Kings, Clerics, Modernists, Terrorists and The Struggle for Saudi Arabia. Nueva York: Hutchinson.

LyNCH, Marc. 2016. The New Arab Wars. Uprisings and Anarchy in the Middle East. Nueva York: PublicAffairs.

MABON, Simon. 2012. "The Battle for Bahrain: Iranian-Saudi Rivalry”. Middle East Policy Council 19, núm. 2 (verano): 84-97. https:// doi.org/10.1111/j.1475-4967.2012.00537.x

Mainuddin, Rolin G. 2016. "Arab Spring and Democratic Transition in the GCC: Continuity amidst Change". Asian Journal of Peacebuilding 4, núm. 2: 161-186. https://hdl.handle.net/10371/ 98884

ManeA, Elham. 2005. Regional Politics in the Gulf. Saudi Arabia, Oman, Yemen. Londres: Saqi. 
NADAL, Martí. 2016. “¿Todos para uno y uno para todos? El Consejo de Cooperación del Golfo en su expansionismo por Oriente Próximo”. El Orden Mundial, 19 de abril de 2016.

Negri, Alberto. 2018. "Gulf Regional Crisis: Qatar-Saudi Arabia Rivalry, Tensions within the Gulf Cooperation Council”. En IEMed Mediterranean Yearbook 2018, 244-246. Barcelona: Instituto Europeo del Mediterráneo.

Nonneman, Gerd. 2005. "Determinants and Patterns of Saudi Foreign Policy: 'Omnibalancing' and 'Relative Autonomy' in Multiple Environments". En Saudi Arabia in the Balance: Political Economy, Society, Foreign Affairs, editado por Gerd Nonneman y Paul Aarts, 315-351. Londres: Hurst.

Nordland, Rod. 2013. "Saudi Arabia Promises to Aid Egypt's Regime”. New York Times, 19 de agosto de 2013.

NurunNabi, Mohammad. 2017. "Transformation from an Oil-based Economy to a Knowledge-based Economy in Saudi Arabia: The Direction of Saudi Vision 2030". Journal of the Knowledge Economy 8, núm. 2: 536-564. https://doi.org/10.1007/s13132017-0479-8

OtTaway, David. 2011. Saudi Arabia in the Shadow of the Arab Revolt. Washington: Woodrow Wilson International Center for Scholars. https://www.wilsoncenter.org/publication/saudiarabia-the-shadow-the-arab-revolt-summer-2011-0

Pollack, Josh. 2002. "Saudi Arabia and the United States, 19312002". Middle East Review of International Affairs 6, núm. 3: 77102.

Pollack, Kenneth M. 2003. "Securing the Gulf”. Foreign Affairs 82, núm. 4: 2-16. https://doi.org/10.2307/20033645

Priego, Alberto. 2015. "Las Primaveras Árabes: la influencia de Qatar y sus relaciones con los Estados del Golfo". Revista UNISCI/ UNISCI Journal 39: 233-252. https://doi.org/10.5209/rev RUNI.2015.n39.51822

RoberTs, David B. 2016. "The Four Eras of Qatar's Foreign Policy”. Comillas Journal of International Relations 5: 1-17. https://doi. org/10.14422/cir.i05.y2016.001

RodríGuez, Daniel. 2018. "Catar y la crisis diplomática en el golfo Pérsico” (Documento Opinión 12/2018). Bie 3. Boletín IEEE 9: 450-469. http://www.ieee.es/contenido/noticias/2018/02/ DIEEEO12-2018.html? locale $=$ es 
SAAB, Bilal Y. 2014. The GulfRising. Defense Industrialization in Saudi Arabia and the UAE. Washington: Atlantic Council. http://www. atlanticcouncil.org/publications/reports/the-gulf-rising-defenseindustrialization-in-saudi-arabia-and-the-uae

SADEGHI-Boroujerdi, Eskandar. 2017. "Strategic Depth, Counterinsurgency, and the Logic of Sectarianization: The Islamic Republic of Iran's Security Doctrine and its Regional Implications". En Sectarianization. Mapping the New Politics of the Middle East, editado por Nader Hashemi y Danny Postel, 159-184. Londres: Hurst.

SALDAÑA, Marta. 2011. "El Golfo ante la "revolución árabe": ¿tiempo para el cambio político?”. ARI 55/2011. Real Instituto Elcano, 17 de marzo. http://www.realinstitutoelcano.org/wps/portal/ rielcano_es/contenido?WCM_GLOBAL_CONTEXT =/elcano/elcaño_es/zonas_es/ari55-2011

Sarto, Amable. 2018. "Implicaciones de la crisis catari"” (Documento Opinión 31/2018). Bie 3. Boletín IEEE 9: 827-840. http:// www.ieee.es/publicaciones-new/documentos-de-opinion/2018/ DIEEEO31-2018.html

SoAge, Ana Belén. 2017. "¿Qué se esconde tras la guerra fría entre Arabia Saudí e Irán?” (Documento Opinión 71/2017). Bie 3. Boletín IEEE 6: 920-938. http://www.ieee.es/contenido/noticias/2017/06/DIEEEO71-2017.html

Ulrichsen, Kristian. 2011. "Saudi Arabia". En Power and Politics in the Persian GulfMonarchies, editado por Christopher M. Davidson, 63-88. Londres: Hurst.

UlrichSEn, Kristian. 2014. Qatar and the Arab Spring. Policy Drivers and Regional Implications. Washington: Carnegie Endowment for International Peace. https://carnegieendowment.org/files/ qatar_arab_spring.pdf

Valentine, Simon Ross. 2015. Force and Fanaticism. Wabhabism in Saudi Arabia and Beyond. Londres: Hurst.

VAtAnKA, Alex. 2012. “The Odd Couple”. Middle East Institute, 26 de marzo. http://www.mei.edu/content/odd-couple

Wezeman, Pieter D. 2018. "Saudi Arabia, Armaments and Conflict in the Middle East”. Stockholm International Peace Research Institute, 14 de diciembre. https://www.sipri.org/commentary/topical-backgrounder/2018/saudi-arabia-armaments-andconflict-middle-east 
Paloma González del Miño es profesora titular de derecho internacional público y relaciones internacionales en la Universidad Complutense de Madrid (UCM). Dirige el Departamento de Relaciones Internacionales e Historia Global de la UCM y el grupo de investigación Relaciones Internacionales Siglo XXI (RIS-XXI). Es miembro numerario del Euro-Mediterranean University Institute, del Centro de Excelencia de la Unión Europea Antonio Truyol, y del Instituto Complutense de Estudios Internacionales (UCM). Ha impartido clases en universidades como Cairo University, Universidad Autónoma de Lisboa, Universidad de Coimbra, Universidad Argentina de la Empresa y Universidad del Salvador (Buenos Aires), Universidad de Varsovia y Academia Nacional de Estudios Políticos y Estratégicos (Santiago de Chile). Líneas de investigación: estudios regionales del mundo árabe-musulmán; relaciones de la Unión Europea con el Magreb y Oriente Medio; política exterior de Estados Unidos con el mundo árabe-musulmán; política exterior de España en el Magreb y Oriente Medio.

https://orcid.org/0000-0002-9710-1750 palomagm@cps.ucm.es

David Hernández Martínez es investigador posdoctoral en el Departamento de Estudios Árabes e Islámicos y Estudios Orientales de la Universidad Autónoma de Madrid, investigador del Taller de Estudios Internacionales Mediterráneos, redactor y analista de El Orden Mundial, y doctor en relaciones internacionales por la Universidad Complutense de Madrid. Cuenta con una estancia de investigación en el Middle East Centre de la London School of Economics and Political Science de Londres. Líneas de investigación: estudios regionales del Magreb y Oriente Medio; relaciones regionales, estructuras de poder, seguridad y sociedad en el Golfo; política exterior de Estados Unidos en Oriente Medio, y política exterior y de seguridad de la Unión Europea en el Magreb y Oriente Medio. Ha 
participado en varios congresos internacionales sobre política y sociedad en el Golfo, política exterior de España en el Magreb y política exterior de Arabia Saudí.

https://orcid.org/0000-0003-1171-1038 david.hernandezm@uam.es 
